\title{
Controlled ovarian stimulation and ultrasound guided follicular aspiration in the baboon (Papio cynocephalus anubis)
}

\author{
Sandor $\mathrm{CSEH}^{\mathrm{a} *}$, Johannah CoRSELLI ${ }^{\mathrm{a}}$, Philip CHAN ${ }^{\mathrm{a}}$, \\ Leonard BAILEY ${ }^{b}$
}

\author{
${ }^{a}$ Department of Ob/Gyn, School of Medicine, Loma Linda University, Loma Linda, CA 92350, USA \\ ${ }^{b}$ Department of Surgery, School of Medicine, Loma Linda University, Loma Linda, CA 92350, USA
}

(Received 25 October 2001; accepted 2 December 2001)

\begin{abstract}
The objective of this study was to investigate whether baboon females respond to an ovarian stimulation protocol incorporating pituitary suppression with a $\mathrm{GnRH}$ agonist (GnRHa) and highly purified human FSH (hphFSH) with follicular development and oocyte maturation. An ovulation induction protocol was applied to 5 adult female baboons with a history of regular menstrual cycles (33-34 days). A long-acting GnRHa implant containing goserelin acetate was placed s.c. on days $22-24$ of their menstrual cycle. Daily hphFSH (75 IU im) treatments were started $\sim 10$ days following menses. When the majority of the follicles were $\geq 5 \mathrm{~mm}$ in diameter and the E2 levels had reached a maximum, hCG (2000 IU i.m.) was administered to induce final maturation of the oocytes and ovulation. 30 to $34 \mathrm{~h}$ after hCG administration, transabdominal follicular aspiration was performed using a variable frequency transvaginal transducer with ultrasound. A total of 71 oocytes were collected (average: 17). 91\% of the oocytes were morphologically normal indicating that they were appropriate for in vitro insemination.
\end{abstract}

ovarian stimulation / highly purified human FSH / GnRH agonist / ultrasound-guided oocyte retrieval / baboon

Résumé - Stimulation ovarienne contrôlée et aspiration folliculaire guidée par ultrason chez le babouin (Papio cynocephalus anubis). L'objectif de cette étude a été d'examiner si une femelle babouin répond au protocole d'une stimulation ovarienne incorporant une suppression hypophysaire grâce à un agoniste de GnRH (GnRHa) et une FSH humaine hautement purifiée (hphFSH) avec développement folliculaire et maturation des oocytes. Un procédé d'induction d'ovulation a été appliqué à 5 babouins femelles adultes ayant des cycles menstruels réguliers (33-34 jours). Un implant de GnRHa à action prolongée contenant de l'acétate de gosereline a été placé en sous cutané les jours 22-24 de leurs cycles menstruels. Les traitements quotidiens de l'hphFSH (75 UI i.m.) ont

* Correspondence and reprints

E-mail: scseh@univet.hu

Mailing address: 1078 Budapest, Istvan u. 2. Hungary 
commencé le $10^{\mathrm{e}}$ jour après la menstruation. Quand la majorité des follicules ont eu un diamètre supérieur à $5 \mathrm{~mm}$ et que le niveau d'œstradiol (E2) a atteint le maximum, hCG (2000 UI i.m.) a été administrée pour entraîner la maturation finale des oocytes et l'ovulation. 30-34 heures après hCG, une aspiration folliculaire transabdominale a été réalisée en la guidant à l'aide d'une sonde ultrasonique à fréquence variable. Au total 71 oocytes ont été recueillis (17 en moyenne). $91 \%$ des oocytes ont eu un aspect morphologique normal indiquant qu'ils étaient utilisables pour une insémination in vitro.

stimulation ovarienne / FSH humain très épuré / GnRH agoniste / récupération d'oocyte guidée par ultrasons / babouin

\section{INTRODUCTION}

Nonhuman primate (NHP) oocytes are retrieved by follicular aspiration before ovulation following ovarian stimulation with foreign gonadotropin (e.g. PMSG or human /menotropin, urofollitropin/) for assisted reproduction [2]. Follicular aspiration in NHP has been performed by laparotomy or laparoscopy [1, 7-10]. Limited data are available on the controlled ovarian stimulation (COS) with a GnRH agonist (GnRHa) and highly purified human FSH (hphFSH) and noninvasive ultrasound-guided follicular aspiration in NHP [6-9]. The data collected will help scientists consider strategies for improving controlled ovarian stimulation protocols for assisted reproduction technology and for animal breeding, conservation and gamete banking.

The objectives of our study were: (1) to investigate whether baboon females respond to an ovarian stimulation protocol incorporating pituitary suppression with a GnRHa and hphFSH with follicular development and oocyte maturation, and (2) to evaluate the effectiveness and safety of transabdominal ultrasound guided oocyte collection in baboons.

\section{MATERIALS AND METHODS}

\subsection{Controlled ovarian stimulation}

A modified human ovulation induction protocol was applied to five adult female baboons (6 to 15 years of age, 12 to $17 \mathrm{~kg}$ ) with a history of regular menstrual cycles (32 to 34 days). A long-acting GnRHa implant containing goserelin acetate (3.6 mg, Zoladex ${ }^{\mathrm{R}}$, ICI Pharma) was placed s.c. on cycle day (CD) 22-24 (luteal phase, CD 1 = the first day of menses) of their menstrual cycles. Menses occurred about 10 days after GnRHa implantation. Daily administration of hphFSH (Fertinex ${ }^{\mathrm{R}}$, Serono; 75 IU i.m.) was started $\sim 10$ days following menses. When the majority of follicles were $>5 \mathrm{~mm}$ in diameter and the E2 levels reached their maximum, 2000 IU hCG (Profasi ${ }^{\mathrm{R}}$, Serono) was administered i.m. to induce final oocyte maturation and ovulation.

\subsection{Serum hormone test}

Serum estradiol (E2) and progesterone (P4) levels were obtained by immunoassay (ELISA) (CPC, Diagnostic Products Corporation) [3].

\subsection{Egg retrieval}

Transabdominal follicular aspiration was performed 30 to 34 hours after hCG administration using a variable frequency transvaginal transducer (Endo- $\mathrm{V}$ transducer, 5.0/6.0/7.5 MHz; Siemens) with an ultrasound system (Siemens Sonoline SI-250). The follicular contents were aspirated into culture tubes using a disposable 17-gauge 30-cm long double-lumen needle connected 
to tubing and a suction pump (Rocket, Alpharetta) set at $100 \mathrm{mmHg}$. Follicles were rinsed with modified human tubal fluid (mHTF, Irvine Scientific) at $37{ }^{\circ} \mathrm{C}$ supplemented with $10 \%$ synthetic serum substitute (SSS, Irvine Scientific). Oocytes were assessed for meiotic maturity $3 \mathrm{~h}$ after collection. Oocytes were examined for the presence of cytoplasmic vesicles and evidence of nuclear maturation. Only oocytes that had extruded a first polar body were considered appropriate for fertilization $[4,9]$. In this preliminary study, ova were used for a variety of pilot experiments. In order to test the fertilizing competence of the oocytes collected, some of them $(n=18)$ were used in a pilot ICSI experiment.

\section{RESULTS}

Serum levels of P4 in all cases of COS were between 10.3 and $13.8 \mathrm{ng} \cdot \mathrm{mL}^{-1}$ at the beginning of the GnRHa treatments indicating that the animals were in the luteal phase, which was suitable to start pituitary suppression [5]. The GnRHa pituitary suppression was evident by low E2 levels $\left(<20 \mathrm{pg} \cdot \mathrm{mL}^{-1}\right)$ and absence of perineal turgeses in the days just prior to FSH injection. The serum E2 levels in all COS cycle except one, increased 4 to 17 -fold to a peak $\left(204,207,306\right.$ and $\left.966 \mathrm{pg} \cdot \mathrm{mL}^{-1}\right)$ around days 9 and 12 post gonadotropin administration. Sonographic evidence of the follicular development was not observed transvaginally or transabdominally until treatment days 9 to 10 when several follicles 2 to $3 \mathrm{~mm}$ in diameter and multiple smaller follicles became visible. Between treatment days 9 and 12, follicle sizes increased to $>5 \mathrm{~mm}$ and the E2 levels reached their maximum (204-966 $\mathrm{pg} \cdot \mathrm{mL}^{-1}$ ), therefore hCG was administered. In a preliminary ultrasound investigation, we compared the transvaginal and transabdominal approach of the ovaries; we found that the latter was better, because in baboons, the ovaries are located much closer to the abdominal wall, which is very thin, than to the vagina $(\sim 1.0 \mathrm{~cm}$ vs. $\sim 3.0 \mathrm{~cm})$. Transabdominal ultrasound guided follicular aspiration was carried out on 4 of the five treated animals between 30 to 34 hours after hCG injection. The procedure was found to be very safe, and the animals returned to normal cycles within 40-60 days after follicular aspiration. One animal did not respond to the treatment and the ovarian stimulation was cancelled. Fourteen, 21, 16 and 20 oocytes $(n=71)$ were collected from 4 animals (average $=17.75 /$ treatment cycle). $91 \%$ of the oocytes collected $(n=64)$ were morphologically normal, all in metaphase 2 and of grade I and II, which are considered appropriate for fertilization $[4,9]$. 18 out of the 64 oocytes were used in a pilot ICSI experiment and a $38.8 \%$ fertilization rate was achieved (7/18).

\section{DISCUSSION}

Our study indicates that baboon females are able to respond with follicular development associated with E2 production and oocyte maturation to a modified human COS protocol incorporating a luteal phase start with a GnRHa followed by injection of hphFSH. Our results demonstrate that a $3.6 \mathrm{mg}$ Zoladex ${ }^{\mathrm{R}}$ implant provided sufficient GnRHa to suppress pituitary control of ovarian function in baboon females and support the observations of others [3]. Our results show that transabdominal ultrasound guided follicular aspiration using a transvaginal transducer is effective and safe for repeated use of oocyte retrieval in the baboon. Using ICSI, we demonstrated that the oocytes collected were able to be fertilized, indicating that sufficient exposure to in vivo conditions was provided to the oocytes for maturation.

\section{ACKNOWLEDGEMENTS}

The authors are grateful to Thomas J. Kuehl Ph.D. (A \& M University, College of Medicine) 
for providing helpful discussions during this project.

\section{REFERENCES}

[1] Bavister B.D., Boatman D.E., In vitro fertilization and embryo transfer technology as an aid to the conservation of endangered primates, Zoo Biol. Suppl. (1989) 21-31.

[2] Dukelow W.R., Vengesa P.N., Primate models for fertilization and early embryogenesis, in: Benirschke K. (Ed.), Primates: The road to selfsustaining populations, Springer-Verlag, New York, 1996, pp. 445-461.

[3] Kang I.S., Kuehl T.J., Siler-Khodr T.M., Effect of treatment with gonadotropin-releasing hormone analogues on pregnancy outcome in the baboon, Fertil. Steril. 52 (1989) 846-853.

[4] Lanzendorf S.E., Zelinski-Wooten M.B., Stouffer R.L., Wolf D.P., Maturity at collection and developmental potential of rhesus monkey oocytes, Biol. Reprod. 42 (1990) 703-711.

[5] McCarthy T.J., Fortman J.D., Boice M.L., Fazlebas A.T., Verhage H.G., Induction of mul- tiple follicular development and superovulation in the olive baboon, Papio Anubis, J. Med. Primatol. 20 (1991) 308-314.

[6] Testard J., Lefevre B., Doumerc S., Olivennes F., Looking for an animal model (Macaca) in Medically Assisted Procreation (MAP), Primatologie 2 (1999) 449-456.

[7] VandeVort C.A., Baugham W.L., Stoufer R.L., Comparison of different regimens of human gonadotropins for superovulation of rhesus monkeys: ovulatory response and subsequent luteal function, J. In Vitro Fertil. Embryo Transfer 6 (1989) 85-91.

[8] VandeVoort C.A., Tarantal A.F., The macaque model for in vitro fertilization: Superovulation techniques and ultrasound-guided follicular aspiration, J. Med. Primatol. 20 (1991) 110-116.

[9] Wolf D.P., Thomson J.A., Zelinski-Wooten M.B., Stoufer R.L., In vitro fertilization embryo transfer in nonhuman primates: the technique and its application, Mol. Reprod. Dev. 27 (1990) 261-280.

[10] Wolf D.P., VandeVort C.A., Meyer-Haas G.R., Zelinski-Wooten M.B., Hess D.L., In vitro fertilization and embryo transfer in the rhesus monkey, Biol. Reprod. 41 (1996) 335-346.

To access this journal online: www.edpsciences.org 